\title{
Interview
}

\section{Closing the loop on the sales engagement cycle - An interview with Mike Fitzsimons of DeskNet}

\author{
Mike Fitzsimons \\ co-founded DeskNet in 1992. With nearly 20 years' experience in the information publishing industry, Mike has become one \\ of the leading experts in the Financial Services space in the area of automated client communications and reporting. During \\ Mike's tenure at DeskNet he has led the development of numerous applications that automate customer communications. \\ ContentWelder ${ }^{\mathrm{TM}}$, DeskNet's enterprise client communications platform, is proven to drive revenue through highly effective \\ pre-sales and post-sales client communications, increase client retention, and reduce operating costs. Mike is a frequent speaker \\ at industry seminars and advises financial services organizations on how to improve customer service and gain a competitive edge \\ via high-impact, automated client communications.
}

\section{ABSTRACT Michael Moon interviews Michael Fitzsimons, CEO and Founder of DeskNet Inc., about the automation of customer communication processes, using examples primarily from the financial industry.}

Journal of Digital Asset Management (2009) 5, 364-374. doi:10.1057/dam.2009.32

Keywords: ROI; engagement; publishing; Financial Services Client communications; automated business processes

MM: We're here with Mike Fitzsimons of DeskNet.

Mike, why don't we start off with a little bit of your personal background, and we'll pick it up from there.

MF: Most of my career has been focused on developing software that automates customer communications and client reporting for the financial services industry. DeskNet's roots were in the traditional publishing space where we first analyzed the processes that publishers go through to produce their products and then we developed software to automate the production of those products. Our early customers were the leading newspaper, magazine and book publishers, such as the Wall Street Journal, magazine publishers like Time Inc., People, Sports Illustrated, and book publishers like Scholastic and Penguin. We also focussed on the retail industry; for example, we were instrumental in helping Macy's West emerge from Chapter 11. DeskNet revolutionized the way Macy's generated its circular advertisements and direct mail, while significantly reducing their operating costs.

We came to realize that the financial services space publishes a far greater amount of information than the publishing industry; however, the two industries share some common goals with respect to the information they publish. DeskNet was able to leverage its publishing experience and bring a new level of quality, service and automation to the financial services industry.

So in summary, my background is in helping companies to exceed their client communications and publishing goals through the development of software products that ultimately enable them to provide a greater level of customer service that can be measured. MM: So you represent then a blend of both the technology and the business side of customer communications and engagement. MF: Yes. That is DeskNet's focus.

DeskNet was founded in 1992, with a mission to automate the end-to-end process of publishing information, from data capture to distribution.

In today's climate in order for new initiatives to be funded they require a measurable Return On Investment (ROI). Fortunately for DeskNet, proving ROI is not difficult with ContentWelder. However, when automating the end-to-end client communications process 
'behind the firewall', the challenge is to overlay a new client communications process on top of a host of legacy systems. Consequently, the sales process encompasses multiple stakeholders and change management.

So for DeskNet, the sales process takes on a consultative approach where oftentimes we have to educate the various stakeholders on the goals of the business as well as the benefits of the new platform specifically as it pertains to them.

Because DeskNet started out as a consulting firm and evolved into a software company we have always been comfortable with balancing the goals of the business with the needs of the business users, operations and IT stakeholders. We attribute our very successful track record to DeskNet's heritage.

MM: Regarding this broad area of sales channel enablement, how do you see it evolving, moving forward? Could you bring us up to speed with how you define sales channel enablement? MF: The sales channel enablement space is about helping companies let their sales team quickly access and personalize information that they might need for a specific target customer, so that they can actually deliver to their clients very meaningful information.

The goal of that being to automate that process, and to allow your entire sales channel to greatly reduce the amount of time it takes to fulfill a customer request.

If a customer wants information about a certain product - especially in the financial industry, how do you access that information and package it all up and deliver it to your customer in as short a period of time as you can?

That's what sales channel enablement is about.

MM: For the most part, sales channel enablement really starts with selling either complex, integrated systems or complexconfigured products and services.

The underlying content must be broken down into smaller and smaller chunks, to allow for a high level of customization and personalization. Do I have that right?

If so, what are some of the implications in terms of content creation and management? MF: I think in sales channel enablement, you are dealing with Customer Relationship Management (CRM) systems that would be housing a lot of information about your customers. There is then the information for the product you want to sell to those customers.

Generally, that information is stored in another system. The production of product information usually has many hands involved due to legal compliance requirements.

We need to make sure we're communicating necessary risk to the customer. All of that information is kept in another platform.

You've got a salesperson that might be using a CRM system to look at different demographics on their customers. Then they reach out to another system where they store profile information on their customers. They need to integrate that.

As they do that, there's a lot of compliance overlay, as well.

Different components are needed. Not everything is always stored in one. There might be more than one product to push out to a group of customers.

There are probably multiple systems inside any business environment that have the information on the different products. You have to integrate this together, and allow a financial advisor to access that information very quickly in order to leverage their CRM system to get that information out to the appropriate clients.

Trying to integrate that - trying to overlay interfaces - so that you can actually look across systems - there are lots of layers of technology that get put into place to bridge those disparate systems together.

MM: So the productivity of that particular frontline advisor really comes down to how quickly that individual can make a clear, cogent request for the information or data or material that they need. And how quickly they can provide answers or information about the status of their customer engagement.

It really gets to an underlying idea of asking for information and providing information in the fastest way possible.

MF: Correct.

In the financial industry, they oftentimes put together seminars to sell financial products. They invite a group of customers to come and learn about particular financial vehicles that these prospects may want to invest in.

A financial advisor might meet 20 or 30 customers out of the 500 attending the seminar. They get their business cards. Each one of those 
customers might have different interests in the kinds of products that they'd like to have follow-up on.

Then the advisor goes back to the office. How does he very quickly pull together all the information that each one of those customers wanted? Momentum is so important in sales. You can hopefully turn around the appropriate information in less than 24 hours to the customer.

MM: It's really critical to build the momentum of that buying process. So that quite literally, every hour you could essentially apply a discount on the likelihood of realizing a transaction.

MF: Perfect. That's correct.

If we can do that quickly, the end result should be that you should be able to reduce the time to apply a transaction to take place. That's oftentimes - as we go in to talking about sales channel enablement - what the ROI of it is. It really does tie in to the ultimate transaction.

MM: And key performance indicators leading to that ultimate transaction?

MF: Correct.

MM: In many cases, financial advisors salespeople - find themselves out on the leading edge of the customer engagement. They don't necessarily have a lot of support behind them.

So sales channel enablement - as we said - is first of all optimizing the productivity of that frontline engagement manager. Secondly, with the goal of maintaining - if not accelerating momentum in that consideration process toward transaction. And thirdly, a sales channel enablement should have in it some mechanism, so that frontline engagement manager can provide meaningful feedback to the folks in the home office.

Can you speak to that notion of starting to gather more meaningful feedback from the frontline in that overall sales channel enablement process?

MF: Sure.

I think that's what marketing and management needs to know. What kind of information is being consumed? What's moving? What's not moving?

MM: Well, there's the top level of what kind of brochures or proposals or prospectuses we're sending out to whom. And of the people that we're sending them out to, how they fit into a product-mix optimization or a customer-mix optimization.

MF: Right.

MM: Specifically, what sort of tools and applications have you seen, such that we're now beginning to incorporate more and more structured data from frontline service providers that flows back into the content-management process?

MF: Here's where we're seeing that happen. I'll use an example.

Recently, Morgan Stanley acquired SmithBarney. You've got in that case a very large front-office sales channel. 22000 financial advisors (FAs) are out there talking to a variety of customers. They're basically pulling that information. This proposal - this content - this information that they're disseminating to their customers.

With our application, we're now about to know exactly what information is being shared with the customers by these 22000 FAs. We know by their performance which FAs are performing and making the most sales. We're able to look at what they're pushing to their customers. What type of information is actually successful by putting out these types of proposals? We're actually seeing a response, and ultimately a transaction, much more quickly. If other sets of FAs are not doing that we're able to make comparisons.

With our applications, the global document portal that these FAs all use to access a variety of information - we're able to track every piece of information that gets disseminated out into the market. But that information, in turn, is then tracked back by the back office. By the business side.

We're able to run analytics now that show, 'These top performers are using this information to communicate to customers ultimately onboard and when it's new business'. As compared to other bits of information.

I think that's the holy grail of all this. Oftentimes a lot of information is put together. Meeting collaterals, pitch books and so on. Some of it just isn't effective.

Ultimately, good salespeople always end up figuring out what works and what doesn't. But if you can run the analytics and find that out a lot sooner, the organization then can be much more proactive at generating the right types of 
information. That's going to help them ultimately transact new business.

What we do with this tool is actually run analytics and compare which pieces of information - which proposals - which collaterals - are more effective than others. The tools that we're applying today actually run those comparisons. So you know which pieces of information are actually working. MM: Now are you correlating those to transaction rates or uptake rates?

MF: Yes. We are. But again, we're using different systems to do that, too. That's the trick of all that.

The ContentWelder product that DeskNet produces is the one that helps automate the generation of all this collateral, and information reports on all sorts of marketing communications pieces.

But then it uploads it so that the entire front-office sales channel has it at its disposal. They can quickly pick and choose what information they want.

When they're tracking what's happening with the sale, they're usually using some form of CRM system. It could be Salesforce.com. Some of these financial firms have their own homegrown systems. At Smith-Barney, it's called NexGen.

That is what houses all the information about their customers.

So that is where the customer transactions are stored. Where the content and collaterals are available they're stored in the DeskNet product ContentWelder.

ContentWelder is able to track usage. While NexGen - the CRM system - is tracking customer transactions. We're the able to marry that information together, and run some very interesting analytics. So we know what's happening with the transactions and we know what's happening with the consumption of that information.

If we start to put those together, and get some pretty interesting analytics, the business is able to figure out what's going on. Which communications are actually effective and which are not.

Morgan Stanley - with this merger going on - is coming to terms with what is in place at Smith-Barney, and now need to pick and choose their new messaging and our collateral.
So Smith-Barney marketing people can sit back and say, 'Well, we know exactly what's effective and what's not'. As the Morgan Stanley brokers come into this picture, we've got a technology that actually tracks all of the usage of the information that we put out there. And we understand what's effective and what's not.

Morgan Stanley was just blown away by that. That's exactly the kind of information that they needed.

MM: Is there any meaningful data in the underlying consumption or use data? Are there any underlying patterns in that data that reveal that the A team - the quota-buster team - is using content in a way that's markedly different than the $\mathrm{B}$ or the $\mathrm{C}$ team?

MF: That is the data that we're just now getting. By the way - these types of things we're talking about, they generally happen in phases.

MM: Sure.

MF: First, let's give them a way to get at the information they need very quickly, and to personalize it. That's Phase One.

In Phase One the technology will allow us to understand what's being pulled out and used.

So now we have some usage analytics.

Phase Two is, 'Okay. Let's look at the usage analytics and what's being pulled out, and tie it into where the CRM system is actually tracking what's going on with the transactions'. Great. 'Now let's marry that information together and see the correlations'.

Phase Three is, 'Hey, now we're suddenly able to analyze best practices'.

I think from a consultative standpoint, when you go in to talk to executives and heads of sales and CMOs, they're trying to do demand creation.

Everyone wants to do that. What you really need to do is say, 'Well, how do we do that? How are we going to track that? How are we going to measure that?' You have to point out that this is going to be a phased approach.

MM: Sure.

MF: Oftentimes they don't have Phase One even taken care of. Or they've put in a system that's making it easier to get this information in the hands of sales, but they have no idea what's really working. What's being used? They have no usage.

They haven't integrated. 
MM: There's also another key idea, there. You need to actually look at all the data, in terms of what's out there and what's being downloaded. That then stimulates or induces a learning process.

As a frontline manager that understands my particular product line and/or my particular customer segments, they start to draw distinctions that were impossible to draw until you actually had the data in front of you to support it.

So there's a learning process. It's almost like peeling an onion one layer at a time. As you start to peel the analytics layer, you reveal new and deeper and deeper levels of pattern and insight. That then formulates a new set of questions or distinctions to go optimize or hunt for in the next layer of data.

So this notion of data mining is really more a process of ongoing discovery - learning application - and asking better questions. Is that a fair summarization?

MF: That's it, in a nutshell.

MM: You were saying that the idea of sales channel enablement is ultimately starting to link selling activity and customer communications to revenue production. More specifically, probably things like number of days to realize a transaction. The number of customer interactions or touchpoints that had to get activated in order to get the transaction and so on.

Can you take us through some of those touchpoints that you find your clients are looking to you to help clarify?

MF: I think that your heads of sales with their systems are going to always be focused on the touchpoints. The timeline it takes. Most CRM systems can generate a report very quickly, if the first touchpoint with this customer was on Day One, and 6 months later, we finally closed this transaction, for example.

MM: Yes. That's simple pipeline analysis. Right?

MF: That's right. However, the problem with most pipeline analyzes is that Marketing has no understanding of them. Marketing's over here saying, 'Well, here's what we think we should create. Maybe this will help'. By packaging these things this way, maybe this is going to help the sales guys be more effective at closing that transaction sooner.
Marketing and sales do not work closely enough to look at it a disciplined manner.

You've got to bring the messaging together with the transaction information. Sales has always had that information as to how long it's taking. Marketing is a little bit bewildered as to, 'We don't quite understand what's working or not'.

Until you bring those two together, where you can actually see a trend, and find what it is that you're doing to make things work.

MM: As we've delved into this area called the 'customer engagement cycle', there are two things that really stand out as particularly cogent.

Most of the data in the CRM system, from a data-management perspective, is highly idiosyncratic to the individual sales executive.

In terms of underlying database hygiene and analytics, it's fairly useless.

MF: Yes.

MM: While I have an accurate name and address and some contact information, I have no economic overlay. I have no household income, credit report kind of stuff typically associated with this particular customer or account.

So typically, what's missing in the CRM system is a marketing database. A database of enriched, uniform and therefore highly usable analytic data - by which then to start to associate with the actual customer transactions. Identifying sub-segments and niches and consumption cohorts by which then to start correlating the unique requirements of this particular segment or cohort to patterns of engagement and consumption patterns - in terms of what content.

And of course, pipeline analytics in terms of mean time to a sale or something.

That said, the other thing that most CRM systems typically lack is any kind of structured, uniform way for a salesperson to communicate to the marketing, 'Here's what I need to close this deal'.

So that form is really more of a structured menu of things that I need to close or to facilitate the buying process.

Oftentimes, sales and marketing go off into two separate universes, because there's no bridge of uniform data - both in terms of, 'Okay, salespeople - who are you talking to?' That's the marketing database. As well as, 'Okay, 
marketing. Here's what I need to close this day up'. Which is more kind of media-consumption requirements.

Does that make sense?

MF: That's correct. And, by the way, I agree with that. I think they're in their own world. It's because they don't have that bridge. They haven't integrated those things together. That's the problem - one of the big problems that DeskNet's trying to solve in the market. MM: So the premise of sales channel enablement, as we've said, first and foremost, is optimizing the productivity of that frontline financial advisor.

Secondly, it's about preserving the buying momentum that initially got activated by the buyer. Third, it's really about understanding how best to organize or orchestrate the resources of an organization, to facilitate the buying process.

And lastly, it's about delving deeper into the analytics that close the loop in terms of the engagement cycle.

With respect to moving forward in terms of sales channel enablement, what sort of innovations have you seen in terms of content creation? Specifically, for some of these more automated workflows and processes?

MF: The real innovation I think that's starting to really take hold in the market is in the content-creation area. There are many different people with different levels of subject matter expertise on any piece of collateral or document that gets generated. So actually it's an innovative way of allowing those people to collaborate and get meaningful information out - on a component-based approach.

If you're putting together a proposal, for example, you actually want multiple people working on that proposal simultaneously. The only way to do that is that each one has been assigned components to work on. Instead of routing an entire document around, where one person writes a piece and routes it to the next...

So the innovations are, when people come to work, they're able to understand what their assignments are and what pieces of content they need to generate. As they're contributing to a process of getting content out and new collateral out.

You can actually collapse the time it takes to produce these types of documents through a component-based workflow approach. Really, in parallel, multiple people are assembling the document by contributing content. And specific components.

MM: I would also then anticipate that these components are at some point initially independent of the medium or format of its expression. So it would go into a print or online or maybe even a mobile or some other sort of display or presentation format.

MF: That's exactly where I'm going. There are two other iterations going out. One is, yes components are being worked on, and they can be output to multiple media.

One of the very popular things today is to actually create microsites. So your customers can actually - through security logon - see. They go to the company's homepage and log on. They get their specific information. With their corporate branding.

It's their own individual microsite, with very rich information and links to other things they can see. But all of that is produced off the same component-based workflow platform.

So the microsite is out there, but the same component-based workflow has produced print output, e-mail, web and so on. That's enormous efficiency. We've sort of gotten away from the notion that there were people just going to the company to help work on web content, and people brought in just to work on print collateral content. That has pretty much gone away with technology innovation.

You've basically got subject matter experts that can write the content. That content through technology - will be massaged, if it has to go out as HTML, XML or in print format. That's all automated.

The other innovation for component-based workflow is that components are shared across different document types.

Just a quick example of a component that might be reused...

Legal disclaimer information might actually be applied globally across certain communication pieces. One legal person could write a global disclaimer. That would be updated and automatically applied across all of the appropriate documents that need that disclaimer. The systems are intelligent enough to know where the component would be applied. 
Companies go through enormous challenges when they have to rebrand. It's, 'Uh-oh where is that logo? What communication piece is across the enterprise?'

They have to change it in so many places. On a component-based workflow platform, you change the logo in one place, and it will disseminate it to all the different outputs.

MM: That would be automated replenishment or automated renewal of content. So we're eliminating a lot of the labor associated with the maintenance of a clear and consistent brand.

MF: Correct.

By the way, we have a customer case study from Invesco. They're rolling out what they call a 'global customer communications platform'.

It produces all sorts of market collaterals and client reports. Fund information. Different products, but one component-based workflow platform. All of this content is being created, and that's being disseminated in a variety of documents across multiple lines of business and so on.

They went through a rebranding. They were Amvescap when DeskNet first started working with them to deploy their global communications platform. They became Invesco and did a rebranding.

The case study actually points it out. They did it entirely by themselves. They were able to change the logo in one place and have it disseminate, as well as their messaging, across all the appropriate documents.

MM: Would it be like 1000 or 5000 documents?

MF: Oh, yes. Thousands of documents. In terms of fact sheets alone, I think they have 412 different funds. Just in one area, all of their client reports... So, thousands of clients getting different types of reports. Yes. It would be in the thousands.

We have a breakdown of the different document types. Again, by making a simple change in one place, they're able to effect that change immediately across. Along with some older technology models that would not go onto this component-based workflow model that would have been a huge undertaking for them, as it had been in the past for them.

It was, by the way, in other areas of Invesco and Amvescap, that were not on the platform. So those other divisions that had not yet on-boarded onto the global communications platform went through enormous expense and cost to effect that change.

But those documents and communications that were on the global customer communications platform (GCCP) - it was a very quick transition.

In the sales channel enablement case with Morgan Stanley and Smith-Barney.... We're thinking, 'Oh, my goodness. We're changing out a logo. How do we do that? There must be templates and collateral everywhere'. What happens is that legal gets backed up - because they have to review everything and make sure everything is within compliance and new disclaimers.

We're able to come in and say, 'Guess what?' You can centrally make this change. It'll affect all documents on the platform. And you'll be able to disseminate that to your 650 branch offices around the country.

There are 22000 financial advisors that will all have the latest disclaimers and the latest logos. It's a centrally managed component-based system.

So - Wow! That's our strategy. How do we get more documents and communications onto this platform for if we have to go through this again?

Oftentimes, and with all the regulation changes that are going on right now, there's going to be more and more of this happening. They're going to have to make sure they can implement it quickly across the enterprise.

You need component-based architecture to do that - and applying that component across all documents is very important.

ContentWelder actually gives you official information as to where this component is used. So you can actually drill into any component in the repository, and it will give you the information. 'This component is used across the following documents in the company'.

So you actually know where components are shared, and you're able to run reports on that.

MM: It would seem to me that then you could start building an ROI case, in terms of discrete components to the overall customer engagement.

The data's going to be there - in terms of, 'Here are all the places that we've used it'.

Then we could probably correlate time-totransaction, based on those proposals that 
contained or didn't contain the various elements.

MF: Correct. You can do that.

MM: Again, that's a fairly sophisticated application of the analytics. But it's something that would logically follow, if in fact you have a complete inventory analysis of all the underlying media components. And you can start correlating those components to levels and patterns of customer engagement.

MF: That's right.

So as you put together these building blocks you can start to do much more sophisticated analytics. So oftentimes it would be hard to initially come in and talk about that in an early-on phase.

MM: Because they wouldn't have yet gone through the process of learning how this data correlates to meaningful events and performance indicators to sale.

MF: That's right.

MM: That makes all kinds of sense.

It also seems to me that in terms of the framework of this overarching narrative of sales channel enablement, we've identified yet another principle - that is performance analysis for components.

Starting to link - with data - discrete components of an otherwise complex customer engagement.

We start to see, in data, the individual and collective contributions. Not just of individual components but individual components within particular configurations.

For the most part, we've been talking about print collateral. Right?

MF: Correct.

MM: We were talking about fund fact sheets and proposals and brochures and so on. But increasingly, the sales enablement entails things like multimedia presentations. Webcasts. Webinars. Flash demonstrations. Immersive buying experiences - whether they're Adobe AIR or SilverLight kinds of applications and so on.

They provide more immersive experiences to individual customers or buyers.

Can you speak to how this component-based workflow starts to support some of these richer Internet applications?

MF: Actually, I believe Invesco was doing exactly that. Much richer. They were using this component-based platform, but they've actually got webcasts to those streaming video components tied into that larger...

So they've got all this information now available in microsites on their website. They're able to really enhance that experience through showing videoclips - interviews with certain FAs on a topic.

It's fascinating to see that come together, now. You've got different types of media. You've got component-based workflow systems. You're pushing out these dynamic microsites. And you've got links now embedded back into all sorts of different multiple media presentations.

MM: Mike - you just mentioned another idea that I want to bring forward. Almost as an operating principle of customer engagement. That is, the evolution or emergence of these microsites.

You've got multiple applications - content feeds and so on - that are wrapped around or assembled and published to a customer persona. Where I define a customer persona as all the information that I know about you, in terms of this structured analytic data. Plus a whole bunch of information that you've provided to me almost in a subscription form - in terms of things that you want to know about. The manner in which you want to know about them. Videos - webcasts - white papers.

As well as, perhaps, that you're a MAC user or a PC user. You're coming in through an iPhone or some other kind of mobile device and so on.

So that customer persona really starts to emerge as the organizing principle or framework for really understanding how to structure and manage these microsites, as immersive engagement theatres.

MF: Exactly.

I think that plays into a great part of our retention strategy. You're providing those customers the information and the experience. What a differentiator! Right?

What Invesco's doing is way out in front of what their competitors are doing, in that regard. They see it as a major differentiator.

MM: In fact, Mike - perhaps we should begin speaking of that and getting them to speak of that not as a customer communications platform, but as a customer engagement platform. 
MF: I agree.

I think that's the right term. I think that's where this has grown and evolved to. It's much more of a customer engagement platform.

We started off as, 'Hey - how are we going to communicate more effectively and get this information out as quickly as possible?' As it's gotten richer and richer and we've started to profile the customers and put together these microsites, that's more the engagement side of this.

So the customers - as they're engaging with Invesco - what they're seeing is so profiled toward their likes and requirements that it's moved to that sort of 'engagement'. I think that's the appropriate term.

MM: So if we bring forward the initial idea of sales channel enablement, where - again - we're optimizing the productivity of that frontline service provider.

As I begin to tell an overall narrative of what it means to be in a relationship with me and my institution, that frontline sales provider is less and less a salesperson, and more and more of a director. More specifically, orchestrating all of the elements of an engagement theatre.

This then calls upon marketing and sales to really come together in a very neat and organic way. That frontline engagement manager starts to orchestrate not just all the content and services within one system, but across multiple systems. And perhaps even across an entire business ecosystem that has services and content from multiple partners.

Then we come back to this idea that we're really orchestrating customer engagement processes across an entire business ecosystem. A company like DeskNet is one of a handful of companies that are really a center of excellence within this business ecosystem for supporting and enabling this customer engagement process. MF: Exactly.

I think that's why companies like DeskNet... We're small...yet it says something to just the fact that we've won enterprise-class rollouts. To the extent of 22000 FAs, 650 branch offices, global customer communication platform rollout in Invesco, Standard Life, MFS Investment Management.

One might expect to see companies playing at IBM's level, there. It's really that center of excellence that we're focused on in this niche space. We're trying to bring that type of innovation into these companies. That's what's exciting about it, I think, for them.

That's where the smaller guys can still play at a very high level.

MM: At a world-class level. Absolutely.

This really gets to the last theme I'd like to develop, here. It's a theme of innovation leadership.

More specifically, the true innovators in most industries tend to come down to small, tightly focused teams that are agile and that employ agile methodologies. Either figuratively or - in fact - literally, in terms of software development methodologies.

They tend to live on the leading edge of a technology. Constantly bringing new technical innovations. Not at the enterprise level in terms of end-to-end process, but in terms of very discrete and narrow workflows within an organization. Scaling up from one automated workflow or activity.

Linking those together. Because part of innovation leadership is that while we innovate from the bottom up, we have a top-down architecture in terms of what we're integrating to. Does that make sense?

MF: Absolutely.

I think that is so accurate.

I think there's another reason why smaller companies use innovators or even have the opportunity. That is that the larger-technology companies lose their nimbleness along the way, as well.

MM: I don't think that larger companies lack vision. I think they have plenty of vision. I don't think they lack for talented people. In fact, they probably have lots of talented people.

If we compare and contrast the actual performance... day-to-day, week-to-week performance of a small, innovation-led team and a larger firm that has plenty of talent and resources and vision... What are the one or two things that really distinguish that smaller, more nimble firm?

It's not just that they're a smaller and nimble firm. Yes of course, that's a material fact. But I think it's because they're able to break things down into small, personal projects. Fifteen-day projects. Forty-five-day projects. Projects that a single person or small group of three people or fewer can execute in a 15 -day or a 45 -day period. 
I think that the root cost or at least one of the root enablements of that business agility that typically small firms enjoy is the ability to see things in terms of nice, small, tightly bound 15 -day projects. To execute monomaniacally against those on a weekly deliverable basis. MF: Absolutely. That's one of the reasons.

I think smaller companies have to look at it that way. They're not going to try to be all things. They know where they can play, and they focus on that.

They've come to understand that they can't do it all. And they'll partner with great alliances where need be.

MM: Another thing about companies such as DeskNet - being a small firm... If I need to talk to the CEO, I call him!

The ability to get things done is like a phone call or an email away.

MF: I think Citigroup did this very, very well. Citigroup has really done very well at hiring small, innovative companies. Because they've come to realize they're nimble. They'll focus on what needs to get done.

And, by the way, that smaller company has a lot more at stake with delivering than trying to work with the larger IBMs of the world which are not as nimble.

It's more difficult for Citi to - say - drive the type of innovation they want through an IBM than through a smaller niche company. They also have come to realize they have a lot of power there in doing that. So they can help shape some of those innovations they'd like to see with a smaller firm.

I use Citigroup as an example; I think that these CIOs have come to realize that working with smaller and innovative companies - the smaller firm is much more open. As you just said - they can call the CEO any time. I get calls on weekends. I'll get calls at night.

They can explain the problem, and they're going to get a straight answer from a smaller, innovative company. I can do that or not.

MM: As a function of having a deep, narrowly defined project, the number of stakeholders that you have to on-board is much smaller. Whereas an IBM or an Accenture will take on big, wide problems. Because that allows them to put together a statement of work that keeps 10,15 or 20 people employed for 6 or 9 months.
Inherent to the business model of the larger consulting firms is that they - by business-model dictate - have to take on big, complex, multiple-stakeholder kind of projects that have tectonic plate type or glacial type of change management inertia associated with them.

You can focus on much more narrow projects with less inertial momentum to the current state. That then requires that the CIO have a larger vision of roadmap - in terms of how this DeskNet project and this project over hereintegrate to a grand roadmap.

So in many respects, you do your best work when you're working with a CIO who has a pretty well-developed service capability roadmap. And understands that this roadmap might have 50 or 60 different discrete services in it. But you're only doing one service in that roadmap, and you're doing it brilliantly as a center of excellence and as a world-class performer, in that one narrow box.

MF: That's right.

Then, within that narrow box, there may be multiple phases as we've discussed. The small, innovative company looks at things in a progressive development cycle.

These big companies oftentimes get distracted when other things are going on. The CIO's got all those other projects going on.

We're able to say, 'Hey - look. Let's put together a three-or five-year maintenance agreement. We've looked at all the innovations you need, and we're going to actually map our development plan to hit those and meet all those phases that we're talking about'.

That little bit of innovation and that commitment is what they're getting from these smaller, innovative companies. Their whole development plan is bringing functionality that knocks off these phases.

So it's less of a headache for the CIO. MM: Therefore, he can plan around it, other projects - to converge with where you're going to be a year from now.

MF: Exactly.

MM: And he has a relative degree of confidence that you're going to hit your marks on time at budget.

MF: That's right.

And again - a smaller firm is not there to play games about the on-time, on-budget. That's where they're nimble. There's a lot more 
at stake than to try to get the technology rolled out to the customer. So obviously, they want to have a good relationship with a client.

MM: That's the notion of innovation. An innovation partner versus a vendor.

A vendor will come in with a statement of work. It's all about fixed price - on time, at budget. Irrespective of whether the requirements changed, or we'd learned new things in the process of building this out.

What you've described is really that of the role of an innovation partner.

As we work through Phase One, new requirements emerge. New technologies emerge. Because you're really driving innovation as opposed to simply delivering a fixed, rigid project deliverable, you can have the conversation with the CIO. To say, 'Hey here's a new requirement. Do you want us to fold this in?' 'Here's a new technology. Do you want us to exploit it?' 'Here's something that was kind of out of scope initially. But with just this incremental effort, we can bring it in to scope. It might extend us another month, in terms of deliverable, but it gives you way more value than just being a month late'.

MF: That's right. That's exactly it.

I think that's why we're still seeing a lot of tremendous success. We are seeing tremendous success with the smaller innovators, gaining large, large customers.

I think it's because the CIOs have become a bit more mature. They're saying, 'Hey. We're actually getting a bigger bang for our buck. Greater results. And we're much more innovative by working with a host of small innovation companies'.

They actually figure out solutions to new requirements that come along, and they're just very nimble at plugging into them and taking advantage.

MM: And working from the bottom up with affected stakeholders. So what they do in fact develop gets used - adopted - and delivers its economic value, as expected. Or beyond. MF: That's right.

By the way, I think IBM has done a brilliant job in saying, 'Hey! Wow! There are all these innovation companies out there. Look at all the partners that they've created'.

What's happening is, they're trying to go in and do that sort of Teutonic play movement in these companies. They don't have the wherewithal to bring every little innovation piece together. Right?

But they've also looked at these innovative companies, and they're using them as an opportunity to understand where innovation is being applied inside these companies.

So they're using their partnership somewhat as a lens - to see what's going on with a bunch of those innovators - into a greater solution suite. Right?

So it's working a bit both ways.

MM: So the IBMs and the Accentures and the Electronic Data Systems (EDS) of the world really are more about orchestrating the resources of a business ecosystem. Providing the strategic integration framework that then defends statements of work or opportunities for companies like DeskNet to come in and do that one hedgehog thing against a 3-year development roadmap. So that IBM can start to orchestrate with the CIO the rest of the ecosystem. Making sure that these things converge in a way that produces synergy and multiple ROI.

MF: That's right.

MM: But I want to thank you again. This has been illuminating. 